\title{
Cardiac abnormalities in hepatic cirrhosis
}

\author{
Alexandru MIHAILOVICI ${ }^{1}$ MD, Gabriel VILCEANU² MD, Lecturer lonut DONOIU ${ }^{3} \mathrm{MD}, \mathrm{PhD}$, \\ Assoc. Prof. Octavian ISTRATOAIE ${ }^{3} \mathrm{MD}, \mathrm{PhD}$, Assist. Univ. Diana TUDORASCU ${ }^{4} \mathrm{MD}, \mathrm{PhD}$, \\ Assoc. Prof. Dan lonut GHEONEA ${ }^{5} \mathrm{MD}, \mathrm{PhD}$ \\ ${ }^{1}$ University of Medicine and Pharmacy, Craiova \\ ${ }^{2}$ Clinical Emergency County Hospital, Craiova \\ ${ }^{3}$ Discipline Cardiology, University of Medicine and Pharmacy, Craiova \\ ${ }^{4}$ Discipline Internal Medicine, University of Medicine and Pharmacy, Craiova \\ ${ }^{5}$ Discipline Gastroenterology, University of Medicine and Pharmacy, Craiova
}

\section{ABSTRACT}

Cirrhotic cardiomyopathy (CCM) is a term used to define a constellation of characteristics that illustrate abnormal cardiac structure and function in patients with cirrhosis. These encompass systolic and diastolic dysfunction, electrophysiological and structural anomalies, both macroscopic and microscopic. At present, the prevalence of CCM remains unknown, mostly because the condition is typically latent and becomes noticeable when the patient is under stress, like exercise, drugs, hemorrhage or surgery. The essential clinical attributes of CCM consist of elevated baseline cardiac output, abnormal response of systolic contraction and diastolic relaxation as an answer to physiological, pharmacological or surgical stress and electrical anomalies (prolonged QT interval). In most cases, diastolic dysfunction predates systolic dysfunction, which tends to manifest only under stressful conditions. CCM diagnosis is still challenging, due to an absence of specific criteria. The prognosis is, as well, difficult to establish, but the severity of the diastolic dysfunction can be a risk marker for mortality.
\end{abstract}

Keywords: liver disease, cirrhosis, cardiomyopathy

\section{INTRODUCTION}

During the evolution of hepatic cirrhosis, the patients develop a slow decline of both the cardiac and circulatory functions, the latter being described for the first time by Kowalsky et al. (1), Murray et al. (2), more than 60 years ago. It has been described that patients with cirrhosis have a hyperdynamic status, characterized by low plasma volume, low systemic vascular resistance and high cardiac output. Besides the dysfunction in systemic circulation, another complication in the evolution of cirrhotic patients is the progressive decline of the cardiac function. In the first phase, cardiac dysfunction does not present any clinical manifestations because of the low systemic vascular resistance and low afterload. It is considered that the direct toxic effect of alcohol in patients with cirrhosis cause, in time, left ventricular dysfunction (3). There are also studies done in early ' 80 s that proved that cardiac changes are not entirely caused by the toxic effect of alcohol. These statements support a new concept called "cirrhotic cardiomyopathy" (CCM) (4), this being a clinical and physiopathological entity, entirely different from alcoholic cardiomyopathy.

\section{DEFINITION OF CIRRHOTIC CARDIOMYOPATHY}

The presence of cardio-circulatory dysfunction in hepatic cirrhosis was first described in 
the 1960s, but was wrongly attributed to alcoholic cardiomyopathy. Only in the last two decades, it has been proved that cardiac dysfunction is also present in non-alcoholic cirrhosis and it is characterized by a decreasing cardiac contractility as an answer to diverse stimuli. So the "cirrhotic cardiomyopathy" term was first introduced to describe this cardiac dysfunction in patients with cirrhosis (5).

CCM is a chronic cardiac dysfunction characterized by electrophysiological anomalies that include the prolonging of the QT interval on the ECG (6), systolic and/or diastolic dysfunction (7, $8)$ but also chronotropic insufficiency $(9,10)$, all these in the absence of a known cardiac disease. Concerning the ventricular function, patients with cirrhosis develop diastolic dysfunction of left ventricle, with normal values of blood pressure.

\section{EPIDEMIOLOGY}

The exact prevalence of CCM remains unknown, given the absence of any uniform criteria of diagnosis. Because many patients with compensated hepatic cirrhosis do not manifest any signs or symptoms, it is hard to estimate the spreading of the disease (11).

Another impediment in finding the incidence of the disease is given by the non-invasive tests that lack the capacity to detect the cirrhosis in early stages (11). Also, another inconvenient in the estimation of prevalence is the fact that this disease is generally latent and it manifests when the patient is under stress, such as exercise, with the use of some drugs, surgery or hemorrhages.

\section{SYSTOLIC FUNCTION}

The systolic function represents a group of phenomena that produce the ejection of blood out of the ventricles. There are numerous techniques, both invasive and non-invasive, utilized for the evaluation of left ventricle (LV) systolic function, one of the non-invasive methods being echocardiography. LV systolic function is quantified by several echocardiographic parameters of global and regional function (12).

In patients with cirrhosis, the systolic dysfunction is, most of the time, latent. At rest, the LV systolic function, evaluated by both invasive and non-invasive methods is normal (13), but in stressful conditions subtle alterations might be detected. New echocardiography techniques can show some changes even at rest (14). One of these techniques is the two-dimensional speckle tracking echocardiography (2D-STE), which allows the evaluation of both global and regional contractility of the LV in 3 orthogonal directions (circumferential, longitudinal, radial) (15). There is an entire series of studies done for this purpose, Sampaio et al. (16), Altekin et al. (17) proving the existence of a low left ventricle shortening fraction (LVSF) despite a normal ejection fraction. Using this technique, Nazar et al. (18) did not find a difference concerning the systolic function in patients with cirrhosis that had various stages of left ventricular diastolic dysfunction.

Concerning the complications of hepatic cirrhosis, patients in the pre-ascites phase have contractile dysfunctions and rising of the stroke volume because of high sodium level (19). These changes are a lot more important in patients with ascites (9), despite decreasing of both preload and afterload.

Measuring systolic time interval is another non-invasive evaluation method of the ventricular contractility. In patients with cirrhosis it has been observed after exertion a rise of the ratio between the preejection and the ejection time of the LV compared to the values registered at rest (10).

Vasoactive drugs have a low cardiovascular effect in patients with cirrhosis, proved over numerous studies. There are some molecules, like angiotensin II that although do not produce a raise in the cardiac output (20), they produce a raise of pressure in pulmonary capillaries and normalization of systemic vascular resistance. Terlipressin, an analogue of vasopressin, is a drug with similar effects (21). These results suggest that by normalizing the afterload, we can uncover a LV dysfunction at rest.

The inotropic and chronotropic functions may be altered in patients with cirrhosis, because of the stimulation of beta-adrenergic agonists. Such agonist is dobutamine, a drug that can produce a slight increase of the cardiac output. Isoproterenol requires a high dose to raise the cardiac output in patients with cirrhosis compared to normal ones $(22,23)$.

\section{THE DIASTOLIC FUNCTION}

The diastole represents the period in the cardiac cycle that starts with the closing of the aortic valve. The diastole phases are represented by the isovolumetric relaxation period, fast 
ventricular filling, slow ventricular filling and late diastolic filling due to atrial contraction (12).

The anomalies of the diastolic function are an early sign of CCM. The mechanisms of these pathological changes remain unclear.

The diastolic dysfunction raises the blood volume in the left atrium (LA), which, in turn, leads to an increase of the transmitral pressure gradient. The diastolic dysfunction of the left ventricle can be diagnosed in 2 ways:

- invasive: diastolic pressure of LV > 16 $\mathrm{mmHg}$ or PCWP (pulmonary capillary wedge pressure) $>12 \mathrm{mmHg}$;

- non-invasive: through echocardiography, this method being the most efficient technique of evaluating the diastolic function. There are 3 types of left ventricle diastolic dysfunction: abnormal relaxation type (low $\mathrm{E}$ wave, increased isovolumetric relaxation time, normal $E$ wave deceleration time, $E / A>1$ ), pseudonormal type (normal $E$ and $A$, normal isovolumetric relaxation time, normal $E$ wave deceleration time, $E / A>1$ ) and the restrictive type (high E wave, low A wave, decreased isovolumetric relaxation time, low $E$ wave deceleration time, $E / A>2$ ).

In patients with CCM, PCWP or the mean left atrial pressure are normal, but there is a significant progressive raise of the cardiopulmonary pressures in relation to the $\operatorname{DDLV}(13,18)$. This raise in the cardiopulmonary pressures is probably related to low afterload or central hypovolemia in patients with cirrhosis (24).

Patients with cirrhosis have numerous changes, such as: dilatation and hypertrophy of the LA, increased thickness of the LV posterior wall and interventricular septum, prolonging of the isovolumetric relaxation time, decreasing of the $E$ wave velocity, prolonging of the $E$ wave deceleration time and increasing $A$ wave velocity (atrial contraction during telediastole) $(8,19,25)$.

In patients with hepatic cirrhosis, the isovolumetric relaxation time and $\mathrm{E}$ wave deceleration time may be prolonged no matter if ascites is present, but a significantly low E/A ratio was observed in patients with ascites $(26,19)$.

The Doppler indexes (E/A ratio) have clear limits $(27,28)$ and rarely allow the exact differentiation between the normal and pseudonormal diastolic filling pattern. Tissue Doppler Imaging (TDI) may overcome these impediments. The speed registered at the ventricular free wall and septum, close to the mitral ring ( $\left.\mathrm{e}^{\prime}\right)$ is a more sensible parameter for the abnormal myocardial relaxation than the mitral variables. It has been proven that TDI speed has a significant correlation with the LV relaxation indexes measured invasively (29).

The American Society of Echocardiography proposed that LV diastolic dysfunction is characterized by the presence of septal e' wave $<8$ $\mathrm{cm} / \mathrm{s}$, lateral $\mathrm{e}^{\prime}<10 \mathrm{~cm} / \mathrm{s}$, LA index volume $\geq 34$ $\mathrm{ml} / \mathrm{m}^{2}$. The severity can be classified by the $\mathrm{E} / \mathrm{e}^{\prime}$ ratio:

- Grade I-E/e' $<8$

- Grade II-E/e' 9-12

- Grade III-E/e' > 13

The prevalence of LV diastolic dysfunction is relatively high in patients with cirrhosis (43$70 \%$ ), even though they have a normal ejection fraction $(30,31)$ and is not related to the etiology of the hepatic disease (32).

\section{ELECTROPHYSIOLOGICAL ANOMALIES}

\section{QT interval prolongation}

QT interval represents the depolarization and repolarization of the ventricles. It is influenced by heart rate, and, as such, it must be expressed like a corrected interval (QTc) (33).

Prolongation of the QT interval (> $440 \mathrm{~ms}$ ) appears in non-cirrhotic patients with portal hypertension and in $30-60 \%$ of cirrhotic patients correlated with the severity of hepatic dysfunction (34). This anomaly is caused by increased action potential duration in at least a fraction of ventricular myocardial cells. On cellular level, the prolonged QT interval is produced by alterations of ionic channels, current in the cardiac plasmatic membranes, resulting in a prolonged repolarization (35). The mechanisms which are likely at the base of prolonged QT interval in patients with hepatic disorders are not entirely known; they are associated, at least in part, with autonomic dysfunction $(36,37)$ and exposure of the heart to humoral factors (cytokines, endotoxins and bile salts) through porto-systemic shunts (38-40).

Bernadi and col. (34) reached the conclusion that the prolonged QT interval is correlated with circulating plasma noradrenaline, which suggests that sympatho-adrenergic anomalies are involved. The clinical relevance of a prolonged QT interval in cirrhosis is not completely understood. It is underlined the fact that this change is associated with a lower rate of survival in 
patients within class A Child-Pugh (34). Other studies failed to confirm these relations (41).

Prolonged QT interval can be reduced during chronic treatment with $\beta$-blockers (42), although these drugs may have harmful effects in patients with cirrhosis and refractory ascites (43-46).

Concerning the liver transplant, it is frequently observed the prolongation of QT interval ( $>500 \mathrm{~ms}$ ), even in patients with initial values $<440 \mathrm{~ms}$ (47). In the posttransplant period, the QT interval must be corrected in about $50 \%$ of patients $(34,48)$.

The insertion of the transjugular intrahepatic portosystemic shunt (TIPS) $(39,43)$ and gastro-intestinal bleedings (49) are correlated with prolonging of the QT interval. Also, there is clinical proof that some drugs (50) must be avoided as much as possible when inserting TIPS or during liver transplant. Patients with cirrhosis and prolonged QT interval have a high risk of developing ventricular arrhythmias, such as torsades des pointes. Studies concerning the dispersion of the QT interval (the difference between the maximal and minimal value of measured $\mathrm{QT}$ intervals) in patients with hepatic cirrhosis reported a normal variation. Also, patients with cirrhosis have a normal day/night QT interval variation (51).

\section{Rhythm and conduction disorders}

Atrial fibrillation and flutter are arrhythmias that are frequently diagnosed in patients with hepatic cirrhosis and are associated with atherosclerosis, hypercholesterolemia and diabetes mellitus (52). It has been reported atrial fibrillation after septic shock and a case of sinus bradycardia with cardiac arrest after transplant in a 58 years old patient with hepatocellular carcinoma and hepatic cirrhosis, which required resuscitation and temporary cardiac stimulation (53).

Josefsson et al. (54) reported several supraventricular arrhythmias in patients with hepatic cirrhosis, such as atrial and junctional extrasystoles, atrial flutter or fibrillation, tachycardia or bradycardia. Pre-transplant evaluation of patients with hepatic cirrhosis identified atrioventricular conduction disorders, such as complete or incomplete left or right bundle branch blocks and intraventricular blocks.

Inflammation may be the substrate for arrhythmias in non-alcoholic fat liver diseases (55). Patients with hepatic fibrosis have high plasmatic inflammatory markers, and many studies indicated the fact that inflammation plays an important role in generating and maintaining atrial fibrillation (56). Nonetheless, Zamirian and others (57) showed that hepatic cirrhosis has a protective role against atrial fibrillation, despite the significant metabolic anomalies, inflammatory syndrome and LA enlargement. The low prevalence of atrial fibrillation observed in their study may be the result of accumulation of anti-arrhythmic or anti-inflammatory substances, which are normally metabolized by a functionally intact liver; this may explain the development of atrial fibrillation after liver transplant (57). It may be also linked to the low prevalence of systemic hypertension or by the administration of drugs (spironolactone and beta-blockers), which reduce the atrial excitation. Spironolactone reduces myocardial fibrosis of the dilated atria and the duration of the P wave, and has an anti-fibrotic effect in the ventricles and reduce the duration of the QT interval $(58,59)$. Beta-blockers are given prophylactically for variceal bleedings, because it leads to vasoconstriction in the splanchnic compartment, raising the preload and improving the diastolic function (60).

\section{Electro-mechanical dissynchronism}

The electro-mechanical systole represents the duration of the total systolic time and has two major components: LV pre-ejection and ejection periods. The pre-ejection period is the interval between the start of the ventricular depolarization until the beginning of LV ejection period. The LV ejection period represents the systolic phase in which the blood is ejected in the arterial system.

The systolic period depends on 4 key factors: heart rate, preload, afterload and the inotropic function. A disruption in the electro-mechanical system leads to dissynchronism between the electric and mechanical systole. Studies that evaluated cardiac function at rest and after an isometric exercise in patients with cirrhosis showed an electro-mechanical delay and increased pre-ejection time. These reports suggest a defect in the electro-mechanical system (61).

A functional electro-mechanical dissynchronism was also confirmed in patients with cirrhosis and prolonged QT interval. It was showed that the electrical systole was longer than the mechanical systole, the latter being normal (62). The clinical signification of these findings remains unclear. The mechanisms of changes mentioned above may be linked to the low 
density of the L-type calcium channel in cardiomyocytes (63). Also, a low response to adrenergic stimulation may affect the excitation-contraction coupling in some cirrhotic patients.

\section{Inotropic and chronotropic incompetence}

Chronotropic incompetence $(\mathrm{Cl})$ is defined by the heart incapacity to proportionally raise the heart rate (HR) as an answer to the metabolic demand. Patients in the first stage of cirrhosis present normal responses to dobutamine (64). Nonetheless, it has been observed a low LV response to dobutamine in cirrhotic patients with normal LV dimensions and normal ejection fraction (65). Other studies on hepatic cirrhosis patients showed heart failure (HF), as a response to exercise, paracentesis, infections and pharmacologic stimuli (66-68). Heart failure is frequently met in patients with cirrhosis, no matter its cause $(69,70)$. There are many evidences of contractile dysfunction in patients with ascites despite low afterload.

Recently, it has been observed that the chronotropic function, estimated as HR to plasmatic noradrenaline ratio, significantly declined in patient with stage II LV distolic dysfunction compared with those without (13). This indicated the existence of HF towards the effective volume of the arterial blood $(18,71)$. The main cause of $\mathrm{HF}$ in patients without a cardiac disease may be linked to the activation of the vegetative nervous system, which does not raise the $H R$. The activation of the sympathetic nervous system is a potential cause of the down-regulation of beta-adrenergic receptors, which leads to the postsynaptic desensitization in the sinoatrial node $(23,72)$.

\section{CARDIAC BIOMARKERS IN HEPATIC DISEASE}

Two types of biomarkers of LV dysfunction have been studied in patients with liver cirrhosis: the atrial natriuretic peptide (ANP) and type $B$ natriuretic peptide (BNP), their quantification being linked to some indexes of the systolic and diastolic functions. ANP is synthetized and secreted in the atria, because of the direct stress on the wall; it's levels are high in patients with raised intravascular volume and LV hypertrophy. The presence of a large LA is considered an indirect marker of the cardiac pressure load (73). The plasmatic concentrations of the ANP are high in patients with cirrhosis and ascites
$(74,75)$, and only in some cases in patients in the pre-ascites phase (76).

BNP is secreted by the ventricles as an answer to the stretch of the muscular cells or because of minor cardiac lesions. Previous studies in patients with liver cirrhosis showed significant levels of BNP and NT-proBNP correlated with the parameters of cirrhosis severity, with abnormal cardiac structure (septal thickness and LV diameter at the end of diastole) (77) and with its function (HR and the QT interval), but not with markers of hyperdynamic circulation (78). The strongest correlation of BNP levels is with end-diastolic pressure, suggesting that the diastolic relaxation is one of the main determining factors of BNP secretion (79). Also, the BNP levels in cirrhotic patients with normal LVEF at rest are also correlated with PCWP and E/e'. It is recommended that patients with NT-proBNP values over $290 \mathrm{pg} / \mathrm{ml}$ are evaluated (80).

Troponin is a structural protein composed of three distinct parts: troponin $\mathrm{C}$, troponin I and $\mathrm{T}$ (cTnT). The troponins are specific markers of myocardial injury, especially cTnT. In some patients with alcoholic cirrhosis, the levels of the troponin I are high and their concentrations are associated with small indexes of the stroke volume and the LV mass, but are not linked to the severity of the cirrhosis or with portal hypertension stage (81). Recently, Wiese et al (82) observed that high levels of CTnT in patients with cirrhosis are correlated with severity indexes of disease and mortality.

Finally, some proteins with enzymatic activities, like myeloperoxidase, galectin-3 (83) and copeptin (84) may also offer useful information in cirrhotic cardiomyopathy.

Even though the prevalence of cardiomyopathy is higher in patients with advanced hepatic disease, no association between the standard hepatic tests was shown, indicating either compromised hepatic synthesis or the presence of portal hypertension and cardiac dysfunction. Nonetheless, when the severity of the liver cirrhosis is evaluated by specific hepatic scores (MELD score or the Child-Pugh classification), associations between the stage of LV diastolic dysfunction, impaired LV systolic function, chronotropic function and MELD scores (13) have been observed (13). Patients with Child-Pugh $>8$ present at least one trait of the CCM (85). Correlations between the severity of the hepatic disease and the presence of ECG changes were also found (34). Thus, patients with advanced liver cirrhosis (high MELD score or Child-Pugh) require additional cardiac investigations. 


\section{DIAGNOSIS}

Because of lack of specific criteria, the CCM diagnosis is difficult. It is known that the EF is a LV systolic function marker. In patients with cirrhosis and cardiomyopathy, LV systolic function, estimated through EF at rest, could be normal. However, the LV systolic dysfunction tends to manifest in stress conditions, although the maneuvers that lead to this change are yet to be standardized. In $25 \%$ of the patients with liver cirrhosis, it has been observed a slow ventricular response to the catecholamine stimulation in dobutamine stress echocardiography (64). These findings indicate the fact that conventional echocardiographic evaluation of the LV systolic function, based on measuring the EF at rest, is not a good contractility index in liver cirrhosis patients. Recently, 2D-STE was proposed as an additional marker for the systolic function. Thus, this method can detect subclinical LV dysfunction (86).

Also, another non-invasive technique used for measuring the cardiac function by representing a 3D structure of the heart is cardiac magnetic resonance imaging (MRI). This approach, like Doppler echocardiography, has the same diastolic function indexes, but with a greater sensibility and reproducibility. At the moment, using the cardiac MRI may just be considered a research technique for evaluating the diastolic function. Magnetic resonance spectroscopy has the potential to recognize the myocardial bioenergetic and metabolic changes.

The LV diastolic dysfunction is relatively easy to diagnose through conventional echocardiography and TDI. In most studies, diagnosis is based on E/A ratio $<1$, prolonged isovolumetric relaxation time (IVRT) and prolonged TDE. A prolonged mitral TDE is an important parameter regarding the LV rigidity. Tissue Doppler shows modifications from normal to LV diastolic dysfunction (87). Most patients with $\mathrm{e}^{\prime}$ (lateral) < $8,5 \mathrm{~cm} / \mathrm{s}^{\circ}$ or e' (septal) $<8 \mathrm{~cm} / \mathrm{s}$ and an enlarged LA $\left(\geq 34 \mathrm{ml} / \mathrm{m}^{2}\right)$ have impaired myocardial relaxation. It was stated the fact that $\mathrm{E}$ (mitral) / $\mathrm{e}^{\prime}$ (annulary) is correlated with rising of PCWP. There is evidence of diastolic dysfunction when $E / e^{\prime}$ ratio $<8$ and $E / e^{\prime}$ ratio $>15$. As such, the $E / e^{\prime}$ ratio and TDE are essentials indexes for grading the diastolic dysfunction. Prolonged QT interval may be of help in identifying patients at risk of CCM, which could be diagnosed with the help of a combination of echocardiographic and electrocardiographic data. On the other hand, markers such as BNP do not seem to be sensitive enough for evaluating subclinical LVDD.

\section{CONCLUSIONS}

Cirrhotic cardiomyopathy is a recently described complication of cirrhosis. Although most patients remain asymptomatic, this pathology could produce significant morbidity and mortality in the presence of stress conditions, like infection, TIPS or liver transplant.

Because of the difficulty in diagnosing this disease, its awareness is important in preventing the CCM complications. Understanding the physio-pathological process of systolic and diastolic functions and of the electrophysiological anomalies in CCM is crucial for continuous development of new, more precise ways to diagnose and treat this condition.

\section{REFERENCES}

1. Kowalski H.J., Abelmann W.H. The cardiac output at rest in Laennec's cirrhosis. J Clin Invest. 1953;32:1025-1033

2. Murray J.F., Dawson A.M., Sherlock S. Circulatory changes in chronic liver disease. Am J Med. 1958; 24: 358-367.

3. Gould L., Shariff M., Zahir M., Di Lieto M. Cardiac hemodynamics in alcoholic patients with chronic liver disease and a presystolic gallop. J Clin Invest. 1969; 48:860-868.

4. Lee S.S. Cardiac abnormalities in liver cirrhosis. West J Med. 1989; 151:530-535.

5. Fede G., Privitera G., Tomaselli T. et al. Cardiovascular dysfunction in patients with liver cirrhosis. Ann Gastroenterol. 2015 Jan-Mar; 28(1): 31-40.

6. Zambruni A., Trevisani F., Caraceni P., Bernardi M. Cardiac electrophysiological abnormalities in patients with cirrhosis. $J$ Hepatol. 2006; 44:994-1002.

7. Valeriano V., Funaro S., Lionetti R. et al. Modification of cardiac function in cirrhotic patients with and without ascites. Am J Gastroenterol. 2000; 95:3200-3205.

8. Finucci G., Desideri A., Sacerdoti D. et al. Left ventricular diastolic function in liver cirrhosis. Scand J Gastroenterol. 1996; 31:279-284.
9. Bernardi M., Rubboli A., Trevisani F. et al. Reduced cardiovascular responsiveness to exercise-induced sympathoadrenergic stimulation in patients with cirrhosis. J Hepatol. 1991; 12:207-216.

10. Wong F., Girgrah N., Graba J. et al. The cardiac response to exercise in cirrhosis. Gut. 2001;49:268-275.

11. Soon Koo B., Fouad R., Lee S.S. Cirrhotic cardiomyopathy Orphanet J. Rare Dis. 2007; 2:15.

12. Ginghina C., Popescu B., Jurcut R. Esentialul in Ecocardiografie, 2013; 25-69.

13. Ruíz-del-Árbol L., Achécar L., Serradilla R. et al. Diastolic dysfunction is a predictor of 
poor outcomes in patients with cirrhosis, portal hypertension, and a normal creatinine. Hepatology. 2013; 58:17321741

14. Kazankov K., Holland-Fischer P., Andersen N.H. et al. Resting myocardial dysfunction in cirrhosis quantified by tissue Doppler imaging. Liver Int. 2011; 31:534540.

15. Nesbitt G.C., Mankad S. Strain and strain rate imaging in cardiomyopathy. Echocardiography. 2009; 26:337-344.

16. Sampaio F., Pimenta J., Bettencourt N., Fontes-Carvalho R. et al. Systolic and diastolic dysfunction in cirrhosis: a tissue-Doppler and speckle tracking echocardiography study. Liver Int. 2013; 33:1158-1165.

17. Altekin R.E., Caglar B., Karakas M.S. et al. Evaluation of subclinical left ventricular systolic dysfunction using two-dimensional speckle-tracking echocardiography in patients with non-alcoholic cirrhosis. Hellenic J Cardiol. 2014; 55:402-410.

18. Nazar A., Guevara M., Sitges M. et al. Left ventricular function assessed by echocardiography in cirrhosis: relationship to systemic hemodynamics and renal dysfunction. J Hepatol. 2013; 58:51-57.

19. Wong F., Liu P., Lilly L., Bomzon A., Blendis $L$. Role of cardiac structural and functional abnormalities in the pathogenesis of hyperdynamic circulation and renal sodium retention in cirrhosis. Clin Sci (Lond). 1999; 97:259-267.

20. Epstein M., Schneider N., Befeler B. Relationship of systemic and intrarenal hemodynamics in cirrhosis. J Lab Clin Med. 1977; 89:1175-1187.

21. Krag A., Bendtsen F., Mortensen C. et al. Effects of a single terlipressin administration on cardiac function and perfusion in cirrhosis. Eur J Gastroenterol Hepatol. 2010; 22:1085-1092.

22. Mikulic E., Muñoz C., Puntoni L.E., Lebrec D. Hemodynamic effects of dobutamine in patients with alcoholic cirrhosis. Clin Pharmacol Ther. 1983; 34:56-59.

23. Ramond M.J., Comoy E., Lebrec D. Alterations in isoprenaline sensitivity in patients with cirrhosis: evidence of abnormality of the sympathetic nervous activity. Br J Clin Pharmacol. 1986; 21:191-196.

24. Henriksen J.H., Schütten H.J., Bendtsen F., Warberg J. Circulating atrial natriuretic peptide (ANP) and central blood volume (CBV) in cirrhosis. Liver. 1986; 6:361-368.

25. Merli M., Calicchia A., Ruffa A. et al. Cardiac dysfunction in cirrhosis is not associated with the severity of liver disease. Eur J Intern Med. 2013; 24:172-176.

26. Pozzi M., Carugo S., Boari G. et al. Evidence of functional and structural cardiac abnormalities in cirrhotic patients with and without ascites. Hepatology. 1997; 26:1131-1137.
27. Nagueh S.F., Appleton C.P., Gillebert T.C. et al. Recommendations for the evaluation of left ventricular diastolic function by echocardiography. Eur J Echocardiogr. 2009; 10:165-193.

28. Salerno F., Cazzaniga M., Pagnozzi G. et al. Humoral and cardiac effects of TIPS in cirrhotic patients with different "effective" blood volume. Hepatology. 2003; 38:13701377.

29. Nagueh S.F., Middleton K.J., Kopelen H.A. et al. Doppler tissue imaging: a noninvasive technique for evaluation of left ventricular relaxation and estimation of filling pressures. J Am Coll Cardiol. 1997;30:1527-1533.

30. Raevens S., De Pauw M., Geerts A. et al. Prevalence and outcome of diastolic dysfunction in liver transplantation recipients. Acta Cardiol. 2014; 69:273-280.

31. Dadhich S., Goswami A., Jain V.K. et al. Cardiac dysfunction in cirrhotic portal hypertension with or without ascites. Ann Gastroenterol. 2014; 27:244-249.

32. Karagiannakis D.S., Papatheodoridis G., Vlachogiannakos J. Recent advances in cirrhotic cardiomyopathy. Dig Dis Sci. 2015; 60:1141-1151.

33. Zambruni A., Di Micoli A., Lubisco A. et al. QT interval correction in patients with cirrhosis. J Cardiovasc Electrophysiol. 2007; 18:77-82.

34. Bernardi M., Calandra S., Colantoni A. et al. Q-T interval prolongation in cirrhosis: prevalence, relationship with severity, and etiology of the disease and possible pathogenetic factors. Hepatology. 1998; 27:28-34.

35. Ward C.A., Ma Z., Lee S.S., Giles W.R. Potassium currents in atrial and ventricular myocytes from a rat model of cirrhosis. Am J Physiol. 1997; 273:G537-G544.

36. Kempler P., Váradi A., Szalay F. Autonomic neuropathy and prolongation of QT-interval in liver disease. Lancet. 1992; 340:318.

37. Mohamed R., Forsey P.R., Davies M.K., Neuberger J.M. Effect of liver transplantation on QT interval prolongation and autonomic dysfunction in end-stage liver disease. Hepatology. 1996; 23:11281134

38. Ytting H., Henriksen J.H., Fuglsang S. et al. Prolonged Q-T(c) interval in mild portal hypertensive cirrhosis. J Hepatol. 2005; 43:637-644

39. Trevisani F., Merli M., Savelli F. et al. QT interval in patients with non-cirrhotic portal hypertension and in cirrhotic patients treated with transjugular intrahepatic porto-systemic shunt. J Hepatol. 2003 38:461-467.

40. Genovesi S., Prata Pizzala D.M., Pozzi M. et al. QT interval prolongation and decreased heart rate variability in cirrhotic patients: relevance of hepatic venous pressure gradient and serum calcium. Clin Sci (Lond). 2009; 116:851-859.

41. Bal J.S., Thuluvath P.J. Prolongation of QTC interval: relationship with etiology and severity of liver disease, mortality and liver transplantation. Liver Int. 2003;23:243-248.
42. Zambruni A., Trevisani F., Di Micoli A. et al. Effect of chronic beta-blockade on QT interval in patients with liver cirrhosis. J Hepatol. 2008; 48:415-421.

43. Wong F., Salerno F. Beta-blockers in cirrhosis: friend and foe? Hepatology. 2010; 52:811-813.

44. Sersté T., Francoz C., Durand F. et al. Beta-blockers cause paracentesis-induced circulatory dysfunction in patients with cirrhosis and refractory ascites: a cross-over study. J Hepatol. 2011; 55:794-799.

45. Sersté T., Melot C., Francoz C. et al. Deleterious effects of beta-blockers on survival in patients with cirrhosis and refractory ascites. Hepatology. 2010; 52:1017-1022

46. Mandorfer M., Bota S., Schwabl P. et al. Nonselective $\beta$ blockers increase risk for hepatorenal syndrome and death in patients with cirrhosis and spontaneous bacterial peritonitis. Gastroenterology. 2014; 146:1680-1690.e1.

47. Shin W.J., Kim Y.K., Song J.G. et al. Alterations in QT interval in patients undergoing living donor liver transplantation. Transplant Proc. 2011; 43:170-173.

48. Carey E.J., Douglas D.D. Effects of orthotopic liver transplantation on the corrected QT interval in patients with end-stage liver disease. Dig Dis Sci. 2005; 50:320-323.

49. Trevisani F., Di Micoli A., Zambruni A. et al. QT interval prolongation by acute gastrointestinal bleeding in patients with cirrhosis. Liver Int. 2012; 32:1510-1515.

50. Roden D.M. Drug-induced prolongation of the QT interval. N Engl J Med. 2004; 350:1013-1022.

51. Hansen S., Møller S., Bendtsen F.J. et al. Diurnal variation and dispersion in QT interval in cirrhosis: relation to haemodynamic changes. J Hepatol. 2007; 47:373-380.

52. Gundling F., Schmidtler F., Zelihic E. et al. Frequency of cardiac arrhythmia in patients with liver cirrhoses and evaluation of associated factors. Z Gastroenterol. 2012; 50:1149-1155.

53. Kobayashi T., Sato Y., Yamamoto S. et al. Temporary cardiac pacing for fatal arrhythmia in living-donor liver transplantation: three case reports. Transplant Proc. 2008; 40:2818-2820.

54. Josefsson A., Fu M., Björnsson E., Kalaitzakis E. Prevalence of pre-transplant electrocardiographic abnormalities and post-transplant cardiac events in patients with liver cirrhosis. BMC Gastroenterol. 2014; 14:65.

55. Ballestri S., Lonardo A., Bonapace S. et al. Risk of cardiovascular, cardiac and arrhythmic complications in patients with non-alcoholic fatty liver disease. World J Gastroenterol. 2014; 20:1724-1745.

56. Yap Y.G. Inflammation and atrial fibrillation: cause or para-phenomenon? Europace. 2009; 11:980-981.

57. Zamirian M., Sarmadi T., Aghasadeghi K., Kazemi M.B. Liver cirrhosis prevents atrial 
fibrillation: A reality or just an illusion? J Cardiovasc Dis Res. 2012; 3:109-112.(PMC free article)

58. Milliez P., Deangelis N., Rucker-Martin C. et al. Spironolactone reduces fibrosis of dilated atria during heart failure in rats with myocardial infarction. Eur Heart J. 2005; 26:2193-2199.

59. Wong K.Y., Wong S.Y., McSwiggan S. et al. Myocardial fibrosis and QTc are reduced following treatment with spironolactone or amiloride in stroke survivors: a randomised placebo-controlled cross-over trial. Int J Cardiol. 2013; 168:5229-5233.

60. Licata A., Corrao S., Petta S. et al. NT pro BNP plasma level and atrial volume are linked to the severity of liver cirrhosis. PLoS One. 2013; 8:e68364.

61. Bernardi M., Rubboli A., Trevisani F. et al. Reduced cardiovascular responsiveness to exercise-induced sympathoadrenergic stimulation in patients with cirrhosis. $J$ Hepatol. 1991; 12:207-216.

62. Henriksen J.H., Fuglsang S., Bendtsen F. et al. Dyssynchronous electrical and mechanical systole in patients with cirrhosis. J Hepatol. 2002; 36:513-520.

63. Zavecz J.H., Bueno O., Maloney R.E. et al. Cardiac excitation-contraction coupling in the portal hypertensive rat. $A m \mathrm{~J}$ Physiol Gastrointest Liver Physiol. 2000; 279:G28-G39.

64. Dahl E.K., Møller S., Kjær A. et al. Diastolic and autonomic dysfunction in early cirrhosis: a dobutamine stress study. Scand J Gastroenterol. 2014; 49:362-372.

65. Kim M.Y., Baik S.K., Won C.S. et al. Dobutamine stress echocardiography for evaluating cirrhotic cardiomyopathy in liver cirrhosis. Korean J Hepatol. 2010; 16:376-382.

66. Ruiz-del-Arbol L., Monescillo A., Jimenéz W. et al. Paracentesis-induced circulatory dysfunction: mechanism and effect on hepatic hemodynamics in cirrhosis. Gastroenterology. 1997; 113:579-586.

67. Lunzer M.R., Newman S.P., Bernard A.G. et al. Impaired cardiovascular responsiveness in liver disease. Lancet. $1975 ; 2: 382-385$.
68. Bernardi M., Trevisani F., Santini C. et al. Plasma norepinephrine, weak neurotransmitters, and renin activity during active tilting in liver cirrhosis: relationship with cardiovascular homeostasis and renal function. Hepatology. 1983; 3:56-64.

69. Kelbaek H., Rabøl A., Brynjolf I. et al. Haemodynamic response to exercise in patients with alcoholic liver cirrhosis. Clin Physiol. 1987; 7:35-41.

70. Grose R.D., Nolan J., Dillon J.F. et al. Exercise-induced left ventricular dysfunction in alcoholic and non-alcoholic cirrhosis. J Hepatol. 1995; 22:326-332.

71. Ruiz-del-Arbol L., Monescillo A., Arocena C. et al. Circulatory function and hepatorenal syndrome in cirrhosis. Hepatology. 2005; 42:439-447.

72. Inglés A.C., Hernández I., García-Estañ J. et al. Limited cardiac preload reserve in conscious cirrhotic rats. Am J Physiol. 1991; 260:H1912-H1917.

73. Tsang T.S., Barnes M.E., Gersh B.J. et al. Left atrial volume as a morphophysiologic expression of left ventricular diastolic dysfunction and relation to cardiovascular risk burden. Am J Cardiol. 2002; 90:12841289.

74. Ginès P., Jiménez W., Arroyo V. et al. Atrial natriuretic factor in cirrhosis with ascites: plasma levels, cardiac release and splanchnic extraction. Hepatology. 1988; 8:636-642.

75. Salerno F., Badalamenti S., Moser P. et al. Atrial natriuretic factor in cirrhotic patients with tense ascites. Effect of large-volume paracentesis. Gastroenterology. 1990; 98:1063-1070.

76. Wong F., Logan A., Blendis L. Systemic hemodynamic, forearm vascular, renal, and humoral responses to sustained cardiopulmonary baroreceptor deactivation in well-compensated cirrhosis. Hepatology. 1995; 21:717-724.

77. Wong F., Siu S., Liu P., Blendis L.M. Brain natriuretic peptide: is it a predictor of cardiomyopathy in cirrhosis? Clin Sci (Lond). 2001; 101:621-628.

78. Henriksen J.H., Gøtze J.P., Fuglsang S. et al. Increased circulating pro-brain natriuretic peptide (proBNP) and brain natriuretic peptide (BNP) in patients with cirrhosis: relation to cardiovascular dysfunction and severity of disease. Gut. 2003; 52:1511-1517.

79. Goonewardena S.N., Blair J.E., Manuchehry A. et al. Use of hand carried ultrasound, B-type natriuretic peptide, and clinical assessment in identifying abnormal left ventricular filling pressures in patients referred for right heart catheterization. J Card Fail. 2010; 16:69-75.

80. Raedle-Hurst T.M., Welsch C., Forestier N. et al. Validity of N-terminal propeptide of the brain natriuretic peptide in predicting left ventricular diastolic dysfunction diagnosed by tissue Doppler imaging in patients with chronic liver disease. Eur J Gastroenterol Hepatol. 2008; 20:865-873.

81. Pateron D., Beyne P., Laperche T. et al. Elevated circulating cardiac troponin I in patients with cirrhosis. Hepatology. 1999; 29:640-643.

82. Wiese S., Mortensen C., Gøtze J.P. et al. Cardiac and proinflammatory markers predict prognosis in cirrhosis. Liver Int. 2014; 34:e19-e30.

83. Sharma U.C., Pokharel S., van Brakel T.J. et al. Galectin-3 marks activated macrophages in failure-prone hypertrophied hearts and contributes to cardiac dysfunction. Circulation. 2004; 110:31213128.

84. Kimer N., Goetze J.P., Bendtsen F., Møller S. New vasoactive peptides in cirrhosis: organ extraction and relation to the vasodilatory state. Eur J Clin Invest. 2014; 44:441-452.

85. Baik S.K., Fouad T.R., Lee S.S. Cirrhotic cardiomyopathy. Orphanet J Rare Dis. 2007; 2:15.

86. Wiese S., Hove J.D., Bendtsen F., Møller S. Cirrhotic cardiomyopathy: pathogenesis and clinical relevance. Nat Rev Gastroenterol Hepatol. 2014; 11:177-186.

87. Rodriguez L., Garcia M., Ares M. et al. Assessment of mitral annular dynamics during diastole by Doppler tissue imaging: comparison with mitral Doppler inflow in subjects without heart disease and in patients with left ventricular hypertrophy. $A m$ Heart J. 1996; 131:982-987. 